\title{
ESTRATÉgias dO CAPITAL PRIVADO NA EDUCAÇÃO BÁSICA PÚBLICA: NOTAS SOBRE A ABRIL EDUCAÇÃO
}

\author{
Luciana Sardenha Galzerano ${ }^{1}$
}

\begin{abstract}
RESUMO
Este artigo resulta de pesquisa de mestrado em andamento financiada pela Fapesp. Objetiva-se expor resultados parciais acerca das estratégias de atuação de grandes grupos empresariais na educação básica pública no contexto da crise do capitalismo. Para tanto, apresentar-se-á o caso da Abril Educação, com particular atenção para a venda de livros didáticos, por meio do Programa Nacional do Livro Didático (PNLD) e, para a oferta dos chamados Sistemas Privados de Ensino para os municípios paulistas, no período 20052014. Pressupõe-se que essas políticas se situam num contexto mais amplo de reforma dos Estados Nacionais, em que o modelo hegemônico neoliberal redefiniu a função estatal, apresentando-se como uma alternativa para a crise do projeto de desenvolvimento capitalista do pós-guerra. As informações apresentadas neste trabalho resultam de sítios eletrônicos do Fundo Nacional de Desenvolvimento da Educação (FNDE), do Tribunal de Contas do Estado de São Paulo (TCESP), do Grupo Abril e da Abril Educação e da mídia de abrangência nacional. Nota-se uma tendência de privatização que expressa movimento global pelo qual o campo dos direitos sociais, garantidos por meio de políticas públicas, e em especial a educação básica, tem se convertido em campo de negócios.

Palavras-chave: Abril Educação; PNLD; Sistemas privados de ensino.
\end{abstract}

\section{STRATEGIES OF PRIVATE CAPITAL IN THE BASIC PUBLIC EDUCATION: NOTES ON ABRIL EDUCATION}

\begin{abstract}
This paper results from a master's degree research in development provided by São Paulo Research Foundation. In the context of the capitalist crisis, the purpose is to present preliminary results about the large business groups' strategies of action in basic public education. Thus, in the period 2005-2014, it will be introduced the case of Abril Education, specially about its textbooks sales (National Program of Textbook - PNLD) and its offers of Private Education Systems to cities of São Paulo State. It presupposes that these policies are in a broader context of National States' reform. The neoliberal hegemonic model redefined the State role and presented itself as an alternative to the crisis of post-war capitalist development project. The information presented in this study results from sites of National Fund of Education Development (FNDE), Audit Office of São Paulo State (TCESP), Abril Group and Abril Education and national media. It is noticed a privatization tendency expressed as a global motion by which the social rights, specially the basic education, have become a business area.

Keywords: Abril Education; PNLD; Private Education Systems.
\end{abstract}




\section{INTRODUÇÃO: A EDUCAÇÃO NO CONTEXTO DA CRISE DO CAPITALISMO}

Este trabalho ${ }^{2}$, desenvolvido no âmbito do Grupo de Estudos e Pesquisas em Política Educacional (Greppe-Unicamp), apresenta resultados parciais de pesquisa de mestrado em andamento desenvolvida pela autora e financiada pela Fapesp. Apresentar-seão considerações sobre a atuação de grandes grupos empresariais de capital privado na educação básica pública, com especial atenção paraa Abril Educação e sua participação na venda de livros didáticos, por meio do Programa Nacional do Livro Didático (PNLD) e, na oferta de Sistemas Privados de Ensino para os municípios paulistas, no período 2005-2014. Os dados advêm de levantamento realizado nos sítios da empresa, na mídia de abrangência nacional, nos sítios do Fundo Nacional de Desenvolvimento da Educação (FNDE) e do Tribunal de Contas do Estado de São Paulo, além de revisão bibliográfica.

Parte-se do pressuposto de que essas políticas se situam num contexto mais amplo de reforma dos Estados Nacionais, em que o modelo hegemônico neoliberal redefiniu a função estatal, apresentando-se como uma alternativa para a crise do projeto de desenvolvimento capitalista do pós-guerra (HOBSBAWM, 1995; HARVEY, 2011).

Chesnais (1997, p.14) afirma que os governos dos Estados capitalistas adotaram políticas de liberalização, desregulamentação e privatização, fornecendo ao capital a liberdade para mover-se no plano internacional. O contexto atual é de mundialização do capital, isto é, de liberdade quase total para o capital desenvolver-se, valorizar-se e acumular-se.

Para Ianni (1996, p.145), esse caráter internacional do capitalismo se efetiva na segunda metade do século XX, "quando adquire todas as características de um modo de produção global". Afirma que o capital se desenvolve e se articula de diferentes formas no processo de reprodução ampliada, no qual os movimentos de concentração e centralização têm papel fundamental. Seguindo essa linha, Chesnais (1997) assevera que o capital está mais concentrado e centralizado do que em qualquer outro período do capitalismo. A concentração é reforçada pelo movimento de centralização mediante fusões/aquisições:

A operação de aquisição/fusão surge da centralização do capital [...] ela se tornou, quase que invariavelmente, uma maneira de o capital já concentrado combater a queda da taxa de lucro absorvendo outras empresas, para juntar os mercados e eventualmente integrar algum elemento da capacidade de produção e de pesquisa tecnológica dessas últimas, mas desmantelando a sua maior parte. (CHESNAIS, 1997, p.29).

Em obra escrita posteriormente, Chesnais (1999, p.258) destaca a emergência de um "regime de acumulação mundial predominantemente financeiro".Nessa direção, Harvey (2012, p.41) afirma:

Cada vez mais liberta das restrições e barreiras regulatórias que até então limitavam seu campo de ação, a atividade financeira pôde florescer como nunca antes, chegando a ocupar todos os espaços. Uma onda de inovações ocorreu nos serviços financeiros para produzir não apenas interligações globais bem mais sofisticadas, como também novos tipos de mercados financeiros baseados na securitização, nos derivativos e em todo tipo de negociação de futuros (HARVEY, 2012, p. 41).

Muitos autores têm se dedicado ao estudo da chamada "financeirização". O debate intensificou-se após a crise desencadeada no mercado imobiliário dos Estados Unidos, em 2008. A despeito das diversas interpretações, de modo geral, os autores tendem a se dividir 
em dois grupos: os que acreditam que a crise é consequência do neoliberalismo (FOSTER, 2009; DUMENIL, LÉVY, 2011;HARVEY, 2013); e os que a veem como uma consequência histórica da lei tendencial de queda da taxa de lucro ${ }^{3}$ (MÉSZÁROS, 2001; SHAIKH, 2011). Sobre as diferentes interpretações, Antunes (2001, p.9) afirma:

Muito já se escreveu sobre a crise. Crise dos subprime, crise especulativa, crise bancária, crise financeira, crise global, réplica da crise de 1929 etc. Floresce uma fenomenologia da crise, na qual o que se falou ontem se torna obsoleto hoje.

A educação acompanha essas transformações econômicas, vide o alto grau de concentração e centralização dos grupos empresariais atuantes nesse âmbito e sua relação com o capital financeiro, por meio dos mercados de ações ou ainda, das fusões com grandes grupos internacionais.Oliveira (2009, p.743) sinalizou a ocorrência desses movimentos no Brasil, sobretudo no ensino superior privado:

No início desta década [anos 2000], ao se identificar que o setor de educação superior sofreria rápida expansão, a atenção dos fundos de investimento voltou-se para essa área, ocasião em que foram constituídos os primeiros fundos de investimento exclusivamente direcionados à educação. Esses fundos têm condições de injetar altas quantias em empresas educacionais, ao mesmo tempo em que empreendem ou induzem processos de reestruturação das escolas nas quais investem, por meio da redução dos custos, da racionalização administrativa, em suma, da "profissionalização" da gestão das instituições de ensino, numa perspectiva claramente empresarial.

Na educação básica pública brasileira também se observa a atuação de grandes empresas, por meio de diferentes estratégias. Pesquisas desenvolvidas no âmbito do Greppe acompanham essa tendência no estado de São Paulo (ADRIÃO, 2009a, 2011, 2012), com destaque para a venda de livros didáticos e de Sistemas Privados de Ensino.

A venda de didáticos está atrelada ao Programa Nacional do Livro Didático (PNLD), programa federal criado em 1985, com o Decreto $n^{\circ}$ 91.542/85 (BRASIL, 1985), e de responsabilidade do Fundo Nacional de Desenvolvimento da Educação (FNDE). Seu objetivo é prover as escolas públicas de ensino fundamental e médio com livros didáticos e acervos de obras literárias, obras complementares e dicionários (FNDE, 2014a, 2014b).

A distribuição possui um ciclo trienal, que contempla anualmente todas as etapas de escolaridade, mas em proporções diferentes, o que significa que a quantidade - maior ou menor - de exemplares distribuídos depende de tal ciclo.O quadro a seguir apresenta essa lógica:

\section{Quadro - Distribuição de livros didáticos (PNLD) ${ }^{4}$}

\begin{tabular}{|c|c|c|c|}
\hline \multirow{2}{*}{ Etapa de escolaridade } & \multicolumn{3}{|c|}{ Aquisição de livros } \\
\cline { 2 - 4 } & Ano 1 & Ano 2 & Ano 3 \\
\hline $\begin{array}{c}\text { Ensino Fundamental } \\
\left(1^{\circ} \text { ao } 5^{\circ}\right)\end{array}$ & Integral & $\begin{array}{c}\text { Reposição } \\
\text { Parcial }\end{array}$ & $\begin{array}{c}\text { Reposição } \\
\text { Parcial }\end{array}$ \\
\hline $\begin{array}{c}\text { Ensino Fundamental } \\
\left(6^{\circ} \text { ao } 9^{\circ}\right)\end{array}$ & $\begin{array}{c}\text { Reposição } \\
\text { Parcial }\end{array}$ & Integral & $\begin{array}{c}\text { Reposição } \\
\text { Parcial }\end{array}$ \\
\hline Ensino Médio & $\begin{array}{c}\text { Reposição } \\
\text { Parcial }\end{array}$ & $\begin{array}{c}\text { Reposição } \\
\text { Parcial }\end{array}$ & Integral \\
\hline
\end{tabular}

Fonte: Elaboração própria com base em FNDE, 2014b. 
Cassiano (2007, p.10) atenta para o fato de que a venda de didáticos é "cíclica", garantida ano a ano, já que está atrelada ao calendário escolar. Nesse sentido, os sistemas de ensino são vistos como um "mercado-alvo" pelas editoras, e o governo, um "comprador privilegiado".

A autora observa um movimento de formação de grandes oligopólios no mercado brasileiro de didáticos. Entre 1985 e 2007, das 64 empresas que disputavam o mercado nos primeiros anos do PNLD, somente 12 permaneceram, sendo que houve casos de incorporação das menores editoras pelas maiores (CASSIANO, 2007). Ela afirma:

[...] vimos o oligopólio no ramo dos didáticos passar das empresas familiares eminentemente nacionais (exceção feita à FTD) para o dos grandes grupos, sendo que o capital internacional num primeiro momento, foi representado pelas empresas espanholas, que já estavam instaladas nos demais países da América Latina e do Caribe [refere-se à Santillana]. (CASSIANO, 2007, p.36)

O PNLD 2014 adquiriu e distribuiu integralmente livros aos alunos dos anos finais do ensino fundamental $\left(6^{\circ}\right.$ ao $9^{\circ}$ ano) e complementou os materiais adquiridos anteriormente para estudantes dos anos iniciais do fundamental $\left(1^{\circ}\right.$ ao $5^{\circ}$ ano $)$ e do ensino médio. Nesse ano, foram investidos $\mathrm{R} \$ 1.212 .945 .073,00$, com mais de 137 bilhões de livros distribuídos e aproximadamente 31 bilhões de alunos beneficiados (FNDE, 2015). A participação das editoras ${ }^{5}$ no PNLD 2014 é apresentada no gráfico a seguir.

Gráfico 1 - Participação das editoras no PNLD, 2014

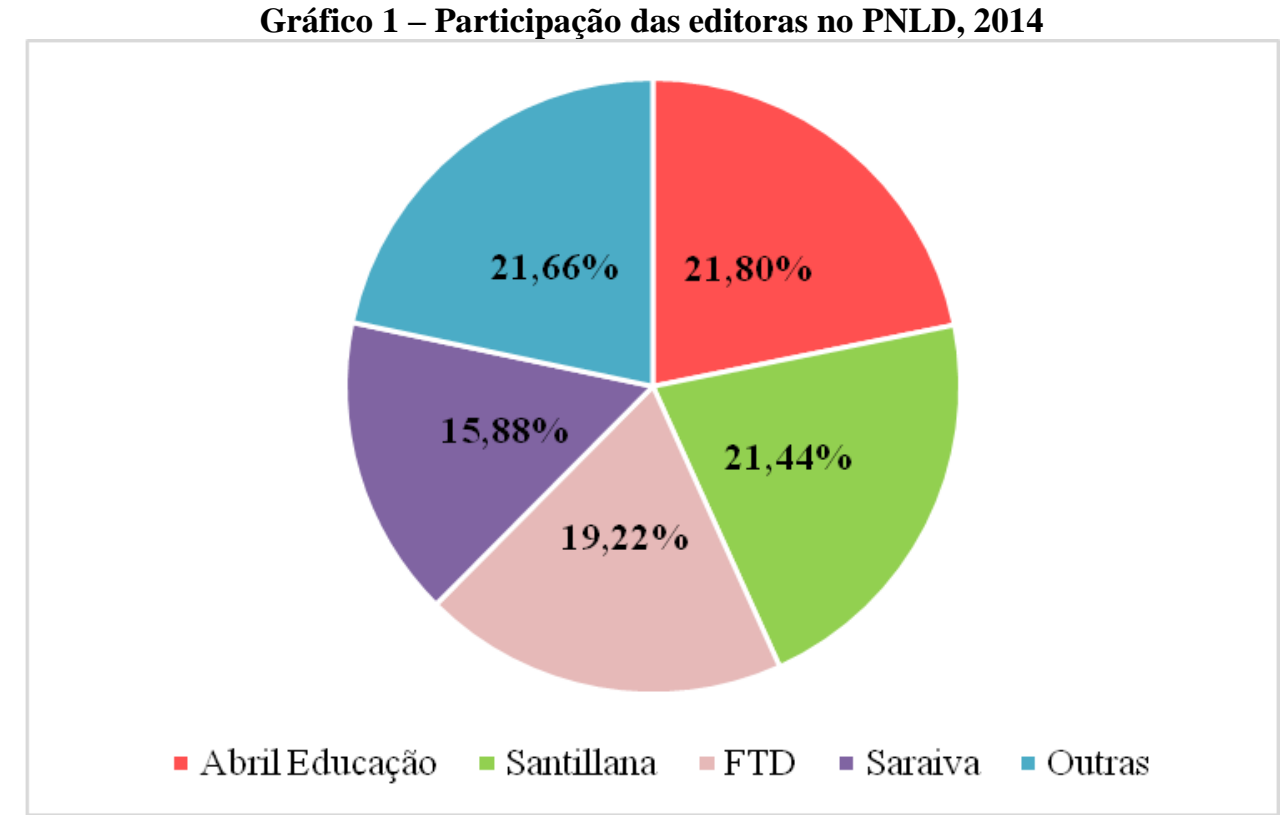

Fonte: Elaboração própria, com base em FNDE, 2015.

As editoras apresentadas no gráfico 1 , em sua maioria, possuem características semelhantes: estão associadas a grupos empresariais estrangeiros ou são companhias com capital aberto em bolsa de valores. A Moderna e a Richmond fazem parte da Editora Santillana, que pertence ao Grupo Prisa, empresa espanhola que atua no Brasil desde 2001 (GRUPO PRISA, 2014). A Ática e a Scipione compõem parte da Abril Educação, que se tornou uma companhia aberta e listada na BM\&Bovespa em 2011 (ABRIL EDUCAÇÃO, 2014a, 2014b) e que, em 2015, passou a ser controlada pela Tarpon, gestora de fundos de investimento (JORDÃO, 2015).A Saraiva também lançou ações na mesma bolsa de valores, em 2006 (SARAIVA, 2014). 
Destaca-se também um movimento mais recente de aquisição dos chamados Sistemas Privados de Ensino (SPE). Pesquisas coordenadas por Adrião (2009a, 2011, 2012) indicaram uma tendência crescente nos municípios paulistas, sobretudo naqueles com até 50 mil habitantes, a realizar parcerias com instituições privadas para adoção de SPE. Deve-se lembrar que:

Ainda que a expressão "sistema de ensino" seja teórica e juridicamente inapropriada para nomear o fenômeno aqui destacado, seu uso tem sido recorrente para designar uma "cesta de produtos e serviços" voltados para a educação básica e ofertados aos gestores públicos ${ }^{6}$. (ADRIÃO; GARCIA, 2010).

O termo sistema é aqui adotado, portanto, com um significado particular: para designar um 'pacote' de produtos e serviços, composto por material didático apostilado para alunos e de apoio para professores, assessoria pedagógica, formação continuada, procedimentos de avaliação (ADRIÃO et al, 2012, p.538).

Em 20117, 251 municípios paulistas adotaram SPE para o ensino fundamental e/ou ensino médio, correspondendo a aproximadamente 39\% do total (ADRIÃO, 2011, 2012). Assim como no mercado de livros didáticos, na adoção de SPE também parece haver maior abrangência dos grandes grupos empresariais, conforme aponta o gráfico a seguir ${ }^{8}$ :

Gráfico 2 - Participação dos grupos empresariais na oferta de SPE, estado de SP, por número de municípios, 2011

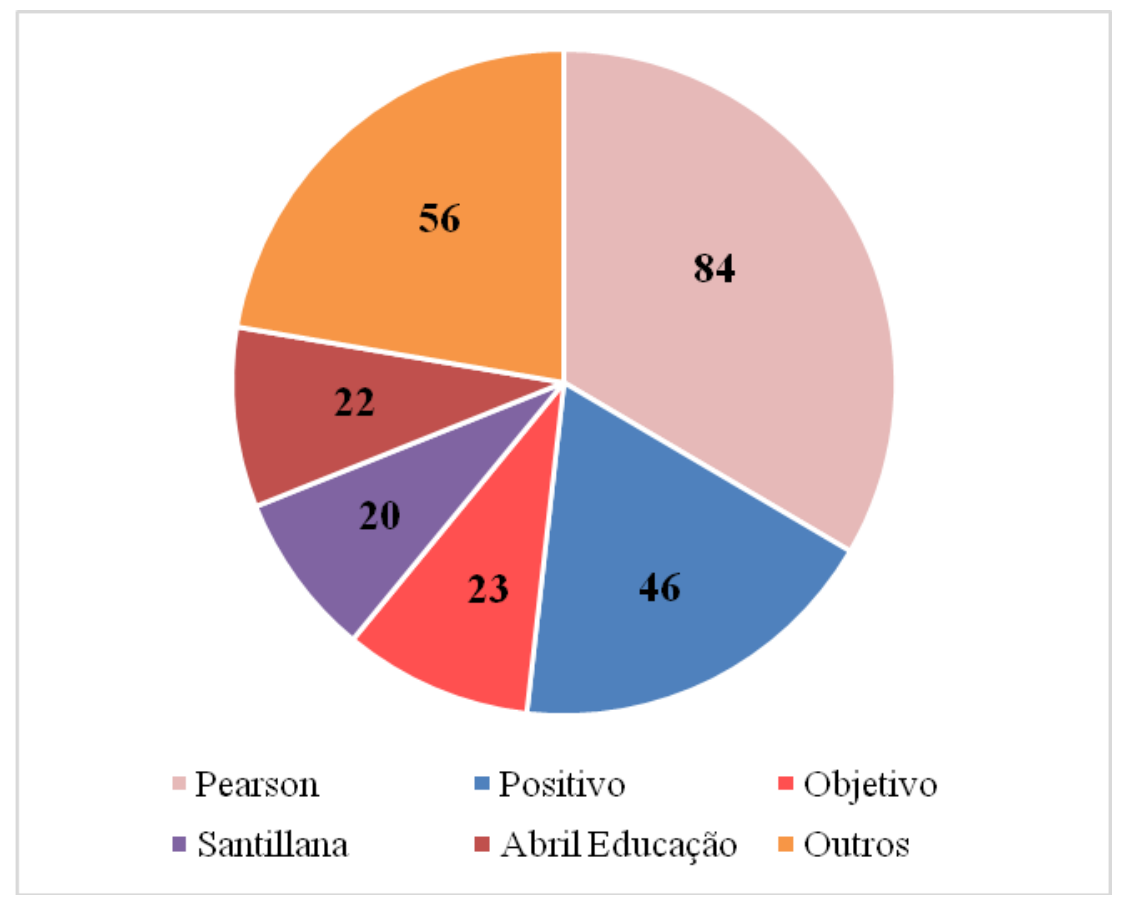

Fonte: Elaboração própria, com base em Adrião $(2011,2012)$ e em Banco de dados parcerias público$\operatorname{privadas}^{9}(2014)$

As características dos grupos empresariais apresentados no gráfico 2 são semelhantes às apontadas no gráfico 1: grandes grupos e capital aberto. A Pearson é uma empresa britânica que adquiriu o Núcleo de Apoio à Municipalização do Ensino (Name) em 2011; antes o Name (empresa responsável pelas parcerias com o setor público) pertencia ao Grupo COC (PEARSON, 2014). Destaca-se também que dois grupos (Abril 
Educação e Santillana) atuam em ambas as políticas, ainda que com o fornecimento de materiais diferentes daqueles fornecidos ao PNLD.

Sabemos que as políticas (PNLD e SPE) possuem grandes divergências, como já apontado em pesquisas coordenadas por Adrião $(2009 \mathrm{a}, 2011,2012)^{10}$, entretanto, o movimento de concentração e de vinculação ao capital financeiro dos grupos empresariais, bem como os interesses do grande capital, nos parecem bastante semelhantes.

Destaca-se que,em estudo divulgado pelo Centro de Estudos da Consultoria do Senado Federal ${ }^{11}$, Britto (2011, p.17), consultora legislativa da área de Educação à época, sugeriu a inclusão dos SPE nos Guias do Livro Didático. Adrião (2009b) já sinalizava a tendência, ainda que não verificada, de ampliação da atuação das empresas fornecedoras de SPE junto à educação pública na medida em que conseguissem integrar o PNLD.

\section{ABRIL EDUCAÇÃO: EDUCAÇÃO PÚBLICA SOB A LÓGICA DO CAPITAL PRIVADO}

O Grupo Abril, pertencente à família Civita, surgiu em 1950 com o lançamento da versão brasileira da revista em quadrinhos $O$ Pato Donald (ABRIL S.A., 2014). No âmbito educacional, a atuação começou em 1960, com a criação do primeiro material didático usado no Movimento Brasileiro de Alfabetização (Mobral) ${ }^{12} \mathrm{e}$, desde então, buscava "melhoria da qualidade da educação brasileira multiplicando as suas linhas de atuação e incentivos no segmento" (ABRIL S.A., 2015).

A Abril Educação surgiu em 2007, como um braço do Grupo Abril (ABRIL S.A., 2015), com o objetivo de unir todos os "ativos relacionados aos negócios da educação" para "explorar o potencial" desse segmento(ABRIL EDUCAÇÃO, 2014d, grifo nosso). A companhia é composta por editoras, sistemas de ensino, escolas e cursos preparatórios, soluções educacionais e ensino de idiomas, atendendo aos setores público e privado de ensino(ABRIL EDUCAÇÃO S.A., 2014b). Sua missão declarada é:

[...] ser a líder, pioneira tecnológica e referência de qualidade na Educação Básica brasileira, em contribuir para a formação dos alunos para o acesso ao Ensino Superior, à empregabilidade e ao exercício pleno da cidadania e em desenvolver programas de formação de valores éticos, morais e de liderança. (ABRIL S.A., 2015).

Em julho de 2011, a Abril Educação tornou-se uma companhia aberta e listada na BM\&FBOVESPA (Bolsa de Valores, Mercadorias e Futuros S.A.); sua oferta pública inicial (IPO) captou um montante de $\mathrm{R} \$ 371,134$ milhões (KAHIL, 2011).A empresa tem atraído fundos de investimentos. Em junho de 2014, a Tarpon ${ }^{13}$, gestora de fundos, adquiriu 19,91\% do capital da companhia (TARPON..., 2014); a operação não implicou em mudanças na administração da empresa. Entretanto, em 2015, a gestora adquiriu o restante das ações pertencentes à família Civita (20,73\%), alcançando 40,65\% do capital total da companhia. Essa operação significou a saída do Grupo Abril do ramo educacional e a assunção do controle da Abril Educação pela Tarpon (GRUPO..., 2015).

$\mathrm{Na}$ educação básica pública, a Abril Educação atua principalmente no fornecimento de livros didáticos(PNLD) e de sistemas privados de ensino.Com relação aos didáticos, a empresa controla as editoras Ática e Scipione, que editam e publicam livros didáticos, materiais de ensino, literatura infantil e juvenil, dicionários, idiomas e paradidáticos(ABRIL EDUCAÇÃO, 2014d). 
Conforme visto no gráficol, a Abril Educação apresentou presença majoritária no PNLD 2014. O gráfico a seguir apresenta a participação de suas editoras no programa federal, entre 2005 e 2014:

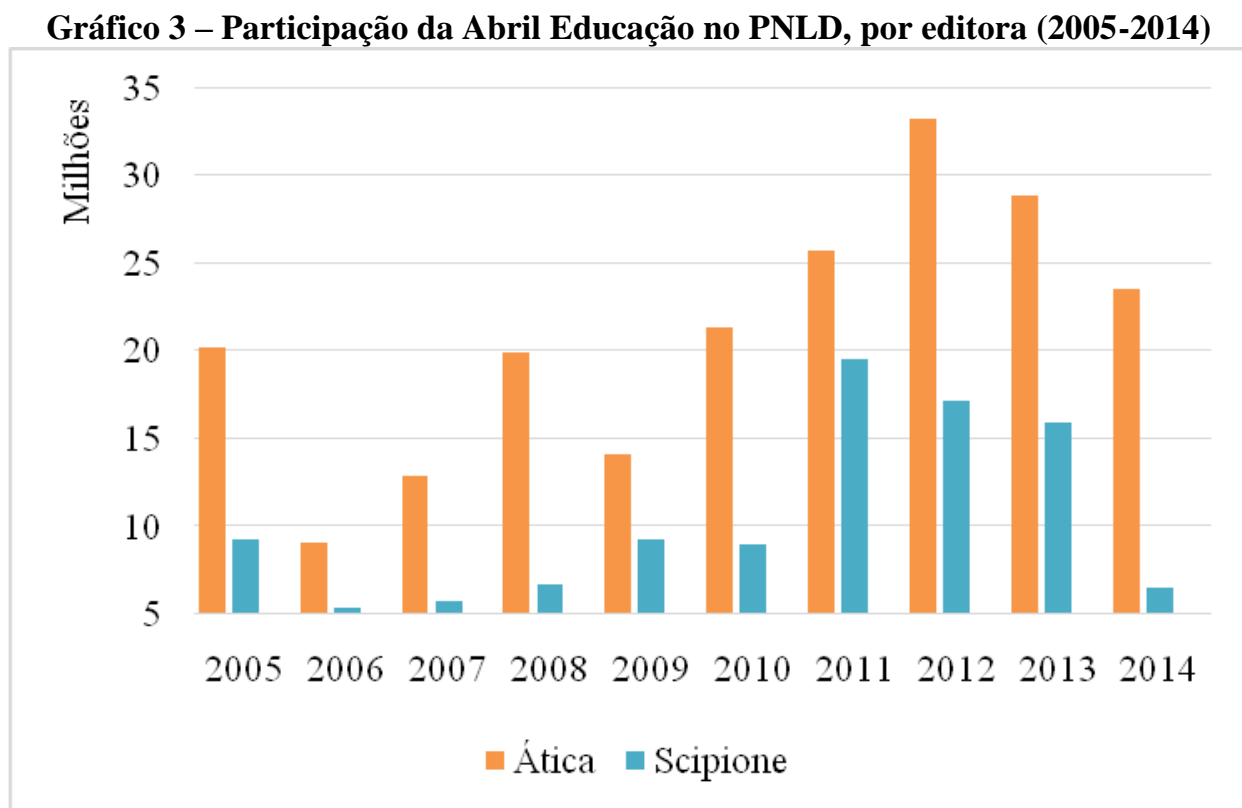

Fonte: Elaboração própria, com base em FNDE, 2015.

Juntas, as editoras resultam em ampla participação da Abril no programa, como apresenta o próximo gráfico:

Gráfico 4 - Participação da Abril Educação no PNLD (2005-2014)

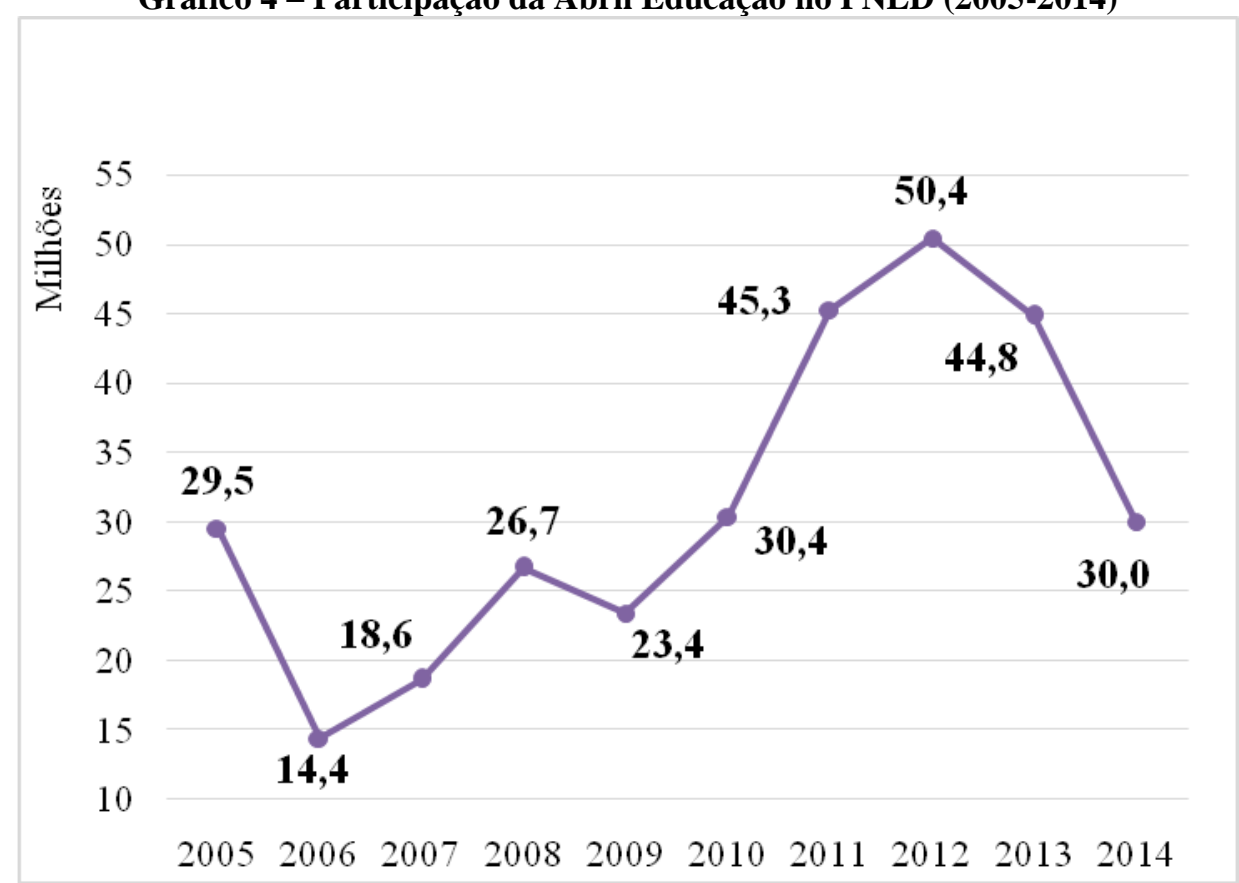

Fonte: Elaboração própria, com base em FNDE, 2015.

Faz-se necessário ressaltar que a queda no número de exemplares vendidos não significa necessariamente uma menor participação da Abril Educação no programa federal, pois, conforme afirmado anteriormente, a venda de livros didáticos segue um ciclo trienal 
de acordo com a etapa de escolaridade, podendo haver variações - para mais ou para menos - no número de exemplares vendidos.

Além da atuação no PNLD, a Abril vêm se inserindo na tendência de oferta de sistemas privados de ensino para as redes pública e privada. São seis marcas: Sistema Anglo de Ensino, Sistema de Ensino SER, Sistema Maxi de Ensino, Sistema pH de Ensino, GEO Sistema de Ensino, Sistema Farias Brito de Ensino (ABRIL EDUCAÇÃO S.A., 2014f). As justificativas da empresa para a atuação com esses sistemas são expressas no trecho que se segue:

O Brasil apresenta crescente tendência pela adoção de Sistemas de Ensino em escolas privadas e públicas buscando ensino de qualidade comprovada e associação a marcas reconhecidas. Esse mercado possui alto potencial de crescimento em função (i) do mercado ainda pouco explorado de escolas públicas; (ii) do crescente número de escolas privadas no País onde Sistemas de Ensino são mais adotados; e (iii) de representar solução eficiente para oferta de qualidade em um mercado com poucos professores bem formados e raros professores com dedicação exclusiva.(ABRIL EDUCAÇÃO S.A., 2014e, grifo nosso).

O gráfico a seguir permite visualizar a participação de dois dos sistemas privados de ensino ofertados pela Abril Educação ${ }^{14}$, no estado de São Paulo:

Gráfico 5 - Número de municípios que adotaram SPE da Abril Educação, por SPE, no estado de São Paulo (2005-2014)

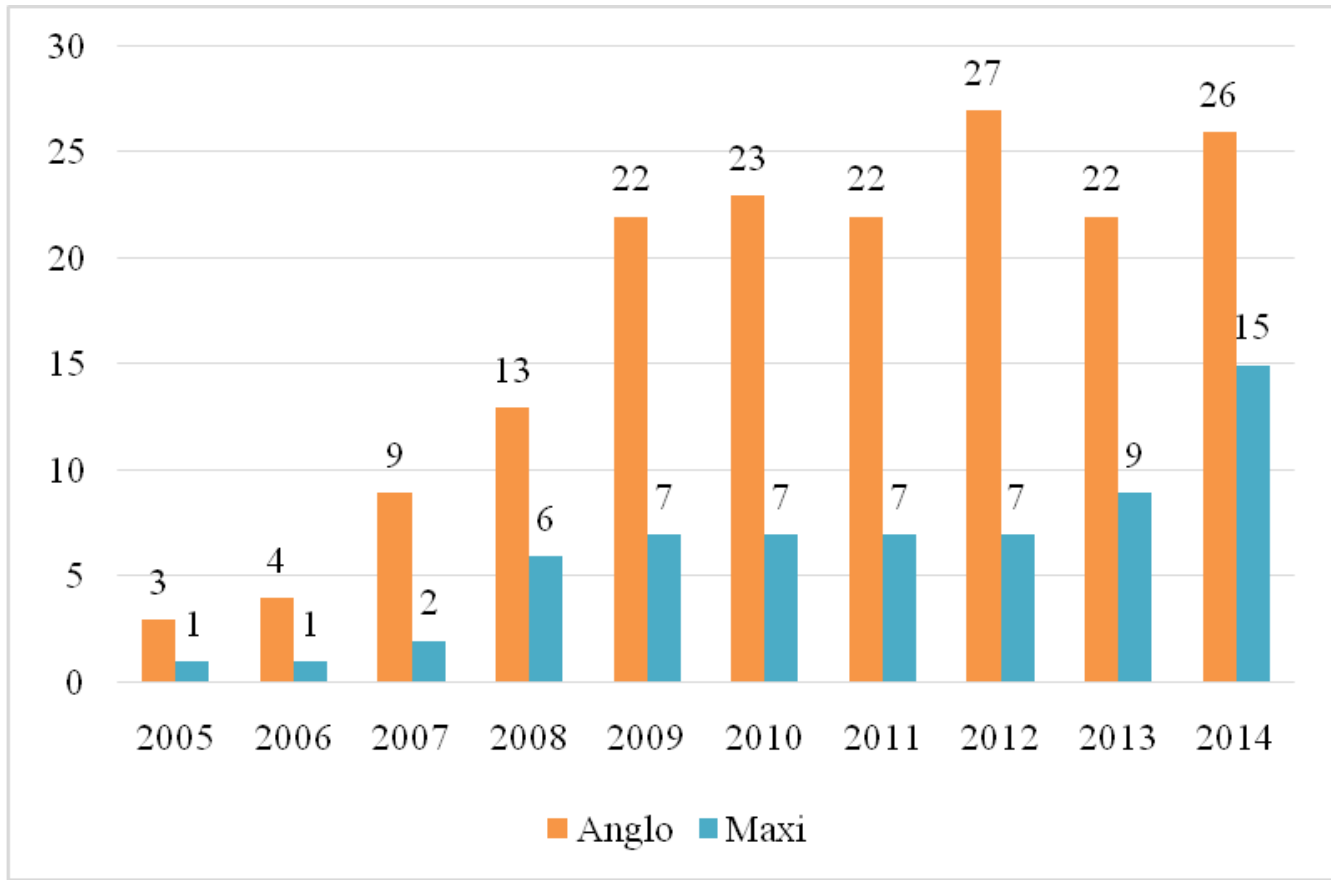

Fonte: Elaboração própria, com base em Adrião (2011, 2012); Banco de dados parcerias público-privadas (2014) e Tribunal de Contas do Estado de São Paulo (2008-2014).

O gráfico 5 permite apreender que a maior participação da Abril Educação acontece, sobretudo, por meio do sistema Anglo. A atuação conjunta de ambos os sistemas (Anglo e Maxi) pode ser visualizada a seguir: 
Gráfico 6 - Número de municípios que adotaram SPE da Abril Educação, no estado de São Paulo (2005-2014)

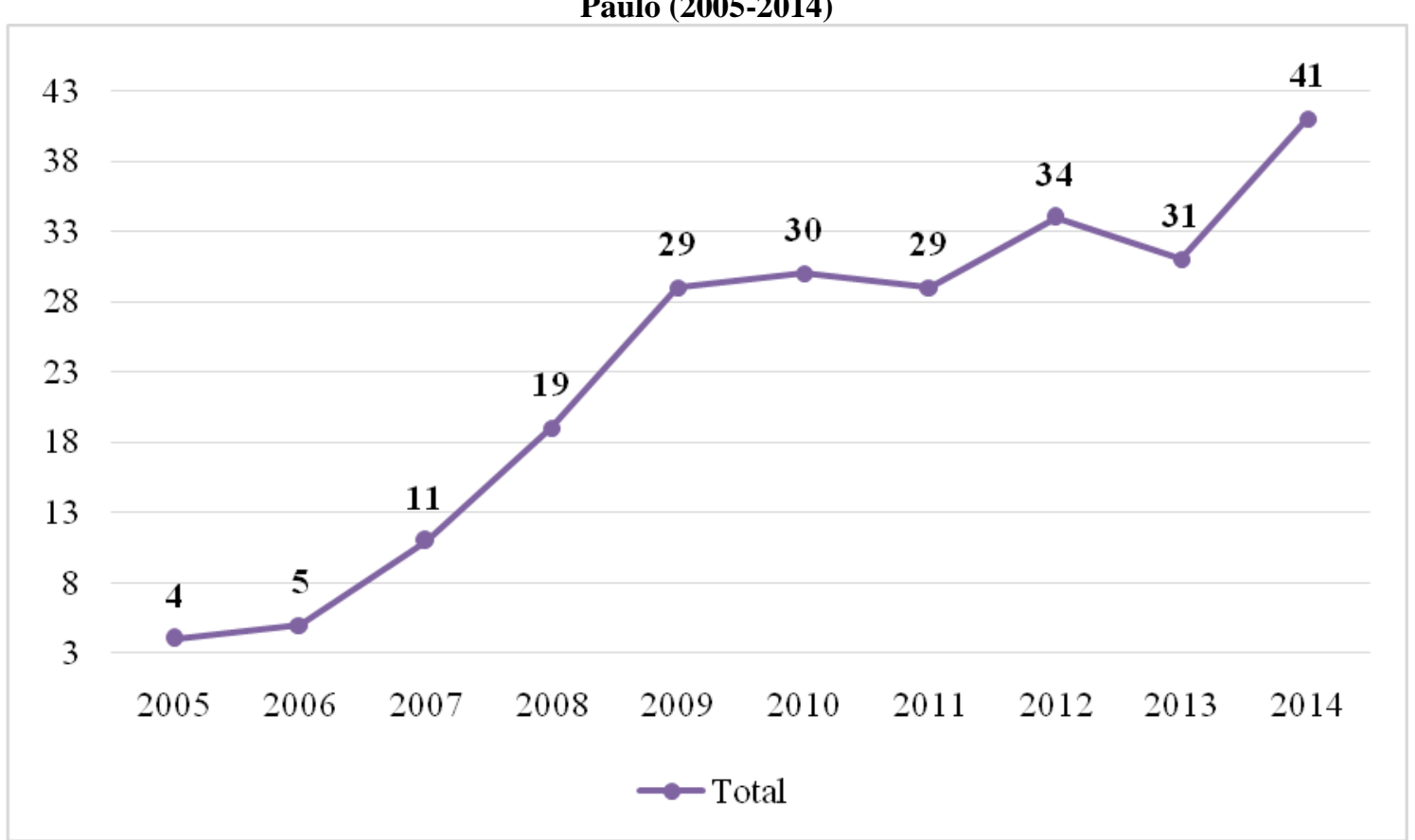

Fonte: Elaboração própria, com base em Adrião (2011, 2012); Banco de dados parcerias público-privadas (2014) e Tribunal de Contas do Estado de São Paulo (2008-2014).

A leitura dos dados apresentados nos gráficos permite-nos apreender a atuação significativa da Abril Educação nas duas políticas de fornecimento de materiais didáticos: o PNLD e os SPE. O grupo atua naquele por meio das editoras Ática e Scipione e nesse, principalmente pelos sistemas Anglo e Maxi.

Matéria divulgada pelo Valor Econômico, em setembro de 2011, comprova o grande interesse da AbrilEducação na educação básica. Manoel Amorim, presidente da empresa à época, declarou que o grupo não tem interesse em faculdades e que seu foco é na educação básica, pois acredita que "uma boa formação é a base para o aluno ingressar em uma universidade ou em um curso profissionalizante" (KOIKE, 2014).

No ano seguinte, em entrevista veiculada pela Revista da Nova Bolsa, Amorim afirmou: "Temos a missão de ser a maior provedora de conteúdo pedagógico do Brasil, acompanhando a criança durante toda a sua vida escolar, além de sermos, desde 2010, líderes no mercado de livros didáticos" (CARNIER, 2012, p10).

\section{CONSIDERAÇÕES SOBRE AS CONSEQUÊNCIAS NO CAMPO EDUCACIONAL}

A análise dos dados apresentados demonstra o grande interesse do capital privado na área educacional no que se refere ao subsídio de recursos públicos para a esfera privada, uma vez que a aquisição de livros didáticos e/ou de SPE é realizada pelo governo federal e municipal, respectivamente. Nesse sentido, concordamos com Adrião (2009b, p.58), quando esta afirma:

A lógica de expansão do capital para este segmento parece ancorar-se em duas grandes condições [...]: a primeira refere-se ao entendimento da educação como um serviço que pode e deve ser comercializável como qualquer mercadoria, para o que as orientações da OCDE são um estímulo adicional em um mercado globalizado (OLIVEIRA, 2009; SGUISSARDI, 2008). Contra isto a ausência de regulação pelo governo brasileiro é um limite evidente. No entanto, se tal tendência se 
limitasse à disputa pelo mercado educacional privado poderíamos entender, ainda que não aceitar, dado ser a educação um valor e um direito. O que agrava ainda mais a situação é que são as redes públicas de educação básica os grandes mercados a serem disputados, dada inclusive a evidente estagnação das matrículas nas instituições privadas de educação básica observada desde meados dos anos 90. (OLIVEIRA; CAMARGO; MANZANO, 1998)

Os grandes grupos empresariais, como é o caso da Abril Educação, atuam como empresascapitalistas, com a especificidade de que as mercadorias e serviços por elas produzidas e negociadas se relacionam com a educação.Se,quando controladora da Abril Educação, a família Civita, com base em seu histórico e experiência na área educacional, afirmava que o intuito da empresa era buscar melhorias e preocupar-se com a qualidade da educação brasileira, atualmente não se pode reiterar esse objetivo, tendo em vista que a empresa foi assumida por uma gestora de fundos de investimentos, a Tarpon, que não possui qualquer histórico ou experiência relacionada à educação.

Essa mudançacomprova o potencial de ação da Abril Educação no mercado financeiro. Para que se tenha noção da dimensão envolvida, basta lembrar que, em sua oferta pública inicial na bolsa de valores, a empresa adquiriu um montante de 371,134 milhões de reais. A financeirização das atividades da Abril Educação, portanto, amplia significativamente o montante de capitais que tem disponível para ser adiantado às suas atividades no mercado educacional. Com isso, potencializa as possibilidades de lucro, ao passo que também garante ganhos para os investidores (donos do capital-dinheiro), que entrarão na divisão da mais-valia produzida pelo complexo de atividades da empresa.

Há que se ressaltarainda as consequências derivadas desse movimento do capital no interior das unidades escolares. Destacamos a influência dos grupos empresariais fornecedores de materiais didáticos no conhecimento que chega às escolas, já que "são os livros didáticos que estabelecem grande parte das condições materiais para o ensino e a aprendizagem nas salas de aula de muitos países através do mundo" (APPLE, 1995, p.81) e também que "é comum dizer-se que o currículo do ensino [...] é determinado pelo livro didático, não o contrário" (CUNHA, 2011, p.596).

Apple (1989) alerta para a não neutralidade do currículo: os conteúdos são selecionados por alguém ou por um grupo que possui determinada visão sobre o que seria o saber legítimo, e tal seleção se produz num contexto de conflitos e tensões. Nesse sentido, os grupos empresariais fornecedores de livros didáticos e de SPE exercem um papel determinante nos conhecimentos que chegam nas salas de aula.

É importante lembrar que organismos internacionais como o Banco Mundial defendem o livro didático como estratégia para melhorar a qualidade do ensino para os países em desenvolvimento:

Livros didáticos e materiais de leitura são a chave para obter resultados pedagógicos em todos os níveis da educação e formação/treinamento, que, por sua vez, são necessários para desenvolver recursos humanos para o desenvolvimento econômico e para a redução da pobreza. (THE WORLD BANK, 2003, p.1, tradução nossa). ${ }^{15}$

Ainda para o Banco Mundial, esses livros didáticos funcionam como compensação para os baixos níveis de formação dos professores:

O livro didático é limitado, já que não é o currículo completo. Entretanto, em países onde os professores não são bem formados/treinados e onde não há outros materiais de aprendizagem nas 
escolas, o livro didático torna-se, efetivamente, o currículo. (THE WORLD BANK, 2003, p.3, tradução nossa, grifo nosso). ${ }^{16}$

Analisando os impactos de práticas curriculares que tendem a padronizar o ensino e, consequentemente, o trabalho pedagógico, Hypolito parecia antecipar a tendência que se tornaria mais clara nos anos 1990 e 2000, com a adoção de SPE:

[...] um "pacote" pedagógico é um fator fundamental na desqualificação do trabalho, no domínio do controle sobre o trabalho e na expropriação do saber do educador. [...] Muitos professores, incentivados pelo sistema, seguem linearmente os livros didáticos. Essa é uma das formas do capital exercer o domínio sobre o conteúdo e a forma da educação. (HYPOLITO, 1991, p.17).

Essa tendência é hoje confirmada pelo mesmo autor, quando afirma que se requisita um professor que colabore "para a efetiva realização dos padrões estandartizados de um currículo necessário para a reestruturação econômica do capitalismo no contexto de globalização" (HYPOLITO, 2010, p.1346).

As fronteiras entre o público e o privado, neste contexto, tornam-se cada vez mais imperceptíveis. O financiamento das políticas aqui destacadas (compra de livros didáticos e de Sistemas Privados de Ensino) propicia ao capital privado apropriar-se de parcelas do fundo público que são estratégicas na garantia de sua rentabilidade, o que torna mais complexo o processo de privatização. A rigor, poder-se-ia afirmar que o Estado financia direta e indiretamente o lucro capitalista.

\section{Referências}

ABRIL S.A. Quem somos - história. 2014. Disponível em: <http://grupoabril.com.br/pt/quem-somos/historia>. Acesso em: 01 jul. 2014.

Conheça a Abril Educação. 2015. Disponível em: <http://grupoabril.com.br/pt/oque-fazemos/Educação>. Acesso em: 02 fev. 2015.

ABRIL EDUCAÇÃO. A Abril Educação. 2014a.Disponível em:<http://www.abrileducacao.com.br/a_abril_educacao.html>. Acesso em: 09 abr. 2014.

Empresas do Grupo. 2014b. Disponível em: <http://ri.abrileducacao.com.br/ptbr/companhia/Paginas/empresas.aspx >. Aceso em: 09 abr. 2014.

ABRIL EDUCAÇÃO. Histórico da Abril Educação. São Paulo, 2014c. Disponível em: <http://www.abrileducacao.com.br/historico.html>. Acesso em: 17 dez. 2014.

.Histórico e Perfil. 2014d. Disponível em: <http://ri.abrileducacao.com.br/ptbr/companhia/Paginas/historico.aspx>. Acesso em: 30 jun. 2014.

Mercado de Atuação. 2014e. Disponível em: <ri.abrileducacao.com.br/ptbr/companhia/Paginas/mercado.aspx>. Acesso em: 30 jun. 2014.

Sistemas de Ensino. 2014f. Disponível em: <www.abrileducacao.com.br/sistemas.html>. Acesso em: 11 fev. 2015. 
ADRIÃO, T. et al. As parcerias entre prefeituras paulistas e o setor privado na política educacional: expressão de simbiose? Educ. Soc., Campinas, v.33, n.119, p.533-549, abr./jun.2012.

(Coord.). Estratégias municipais para a oferta da educação básica: uma análise das parcerias público-privado no estado de São Paulo. 2009a. 366p. Relatório de Pesquisa - Instituto de Biociências da Unesp, Rio Claro.

Indicações e reflexões sobre as relações entre esferas públicas e privadas para a oferta educacional no Brasil. Pol. Educ., Porto Alegre, v.3, n.1, p.48-64, 2009b.

(Coord.). Sistemas apostilados de ensino e municípios paulistas: o avanço do setor privado sobre a política educacional local. 2011. 109p. Relatório de Pesquisa - Unicamp, Campinas.

Sistemas apostilados de ensino e municípios paulistas: o avanço do setor privado sobre a política educacional local. Fase 2. 2012. 86p. Relatório de Pesquisa - Unicamp, Campinas.

. ; GARCIA, T. Sistema Apostilado de Ensino. In: OLIVEIRA, D. A; DUARTE, A. C.; VIEIRA, L. F. (Org.). Dicionário: trabalho, profissão e condição docente. Belo Horizonte, UFMG, 2010. CD ROM.

ANTUNES, R. Introdução: a substância da crise. In: MÉSZÁROS, I. A crise estrutural do capital. $2^{\mathrm{a}}$ ed. rev. e ampl. São Paulo: Boitempo, 2011, p.9-16.

APPLE, M. Educação e poder. Porto Alegre: Artes Médicas, 1989.

Trabalho docente e textos. Porto Alegre: Artes Médicas, 1995.

Banco de dados parcerias público-privadas[Internet].1996-2011. Disponível em: <http://www.fae.unicamp.br/greppe/bd/pesquisas/pesqdados.php> Acesso em: 8 abri. 2014.

BRASIL. Decreto n. 91.542, de 19 de agosto de 1985. Institui o Programa Nacional do Livro Didático, dispõe sobre sua execução e dá outras providências. Diário Oficial da União, Brasília, 20 de agosto de 1985.

BRITTO, T. F. O livro didático, o mercado editorial e os Sistemas de Ensino Apostilados. Textos para discussão - Centro de Estudos da Consultoria do Senado, Brasília, n. 92, jun. 2011. Disponível em: <http://www12.senado.gov.br/publicacoes/estudos-legislativos/tiposde-estudos/textos-para-discussao/td-92-o-livro-didatico-o-mercado-editorial-e-os-sistemasde-ensino-apostilados/view>. Acesso em: 10 maio 2014.

CARNIER, T. Estar em bolsa ajuda a reforçar o otimismo. Revista da Nova Bolsa, São Paulo, n.13, p.6-11, 2012. Disponível em: <http://www.bmfbovespa.com.br/Revista/Edicoes/revista-nova-bolsa-13.pdf >. Acesso em: 14 maio 2014.

CASSIANO, C. F. O mercado do livro didático no Brasil: da criação do Programa Nacional do Livro Didático (PNLD) à entrada do capital internacional espanhol (1985- 
2007). 2007. 234p. Tese (Doutorado em Educação) - Pontifícia Universidade Católica de São Paulo.

CHESNAIS, F. (Org.). A mundialização financeira: gênese, custos e riscos. São Paulo: Xamã, 1999.

. Capitalismo de fim de século. In: COGGIOLA, O. (Org.). Globalização e socialismo. São Paulo: Xamã, 1997.

CUNHA, L. A. Contribuição para a análise das interferências mercadológicas nos currículos escolares. Rev. Bras. Ed. Rio de Janeiro, v.16, n.48, p.585-607, set./dez.2011

DUMÉNIL, G.; LÉVY, D.The crisis of early 21st century: a critical review os alternative interpretations. Disponível em: <http://www.jourdan.ens.fr/levy/>. Acesso em: out. 2014

FNDE. Apresentação. Disponível em: <http://www.fnde.gov.br/programas/livrodidatico/livro-didatico-apresentacao>. Acesso em: 09 abr. 2014a.

- Dados estatísticos. Disponível em: <http://www.fnde.gov.br/programas/livrodidatico/livro-didatico-dados-estatisticos>. Acesso em: 09 abr. 2015.

Histórico. Disponível em: <http://www.fnde.gov.br/programas/livrodidatico/livro-didatico-historico>. Acesso em: 09 abr. 2014b.

FOSTER, J. B. Financeirização do capital e a crise. Outubro, Campinas, n.18, p.8-41, jan./jun. 2009

GRUPO ABRIL. Relatório de desempenho e sustentabilidade 2013 do Grupo Abril: uma nova perspectiva. 2013.2 Disponível em: <http://grupoabril1.abrilm.com.br/relatorioabril2013port.pdf $>$. Acesso em: 02 fev. 2015.

GRUPO Abril vende operação de educação para Fundos Tarpon. G1, Economia, São Paulo, 09 fev. 2015.20 Disponível <http://g1.globo.com/economia/negocios/noticia/2015/02/fundos-da-tarpon-fechamaquisicao-de-controle-da-abril-educacao-20150209075504229921.html>. Acesso em: 10 mar. 2015.

GRUPO PRISA. Santillana. Disponível em: <http://www.gruposantillana.com.br/>. Acesso em: 09 abr. 2014.

HARVEY, D. Condição pós-moderna: uma pesquisa sobre as origens da mudança cultural. 21. ed. São Paulo: Edições Loyola, 2011.

O neoliberalismo: história e implicações. $3^{\text {a }}$ ed. São Paulo: Loyola, 2012. Os limites do capital. São Paulo: Boitempo, 2013.

HOBSBAWM, E. Era dos extremos: o breve século XX: 1914-1991. 2. ed. São Paulo: Companhia das Letras, 1995. 
HYPOLITO, A.Políticas curriculares, Estado e regulação. Educ. Soc., Campinas, v.31, n.113, p.1337-1354, out./dez.2010.

.Processo de trabalho na escola: algumas categorias para análise. Teor. Educ., Porto Alegre, n.4, p.3-21, 1991.

IANNI, O. A dialética da globalização. In: Teorias da globalização. $3^{\mathrm{a}}$ ed. Rio de Janeiro: Civilização Brasileira, 1996, p. 135-162.

JORDÃO, P. Fundos da Tarpon fecham aquisição de controle da Abril Educação. Reuters Brasil, 9 fev. 2015. Disponível em: <http://br.reuters.com/article/businessNews/idBRKBNOLD11320150209>. Acesso em: 10 mar. 2015.

KAHIL, G. Ações da Abril Educação estreiam na Bovespa. Exame, São Paulo, 26 jul. 2011. Disponível em: <http://exame.abril.com.br/mercados/noticias/acoes-da-abrileducacao-estreiam-na-bovespa>. Acesso em: 17 dez. 2014.

KOIKE, B. Abril Educação vai investir em apostilas. Valor Econômico, São Paulo, 05 set. 2011. Disponível em: <http://www.valor.com.br/brasil/997804/abril-educacao-vai-investirem-apostilas>. Acesso em: 14 maio 2014.

MARX, K. O Capital: crítica da economia política. Livro 3: o processo global de produção capitalista. v.4. $6^{\text {a }}$ ed. Rio de Janeiro: Civilização Brasileira, 1991.

MÉSZÁROS, I. A crise estrutural do capital. $2^{\mathrm{a}}$ ed. rev. e ampl. São Paulo: Boitempo, 2011, p.9-16.

OLIVEIRA, D,; CAMPOS, E. O Zeca, os caras... E o Abilio. Época Negócios, 12 out. 2013.

em:

$<$ http://epocanegocios.globo.com/Informacao/Visao/noticia/2013/08/o-zeca-os-caras-e-oabilio.html>. Acesso em: 17 dez. 2014.

OLIVEIRA, R. P. de. A transformação da educação em mercadoria no Brasil. Educação e Sociedade, Campinas, v. 30, n. 108, p. 739-760, out. 2009.

PEARSON. Produtos e serviços. Disponível em: <http://portal.pearson.com.br/portal/pearson/educacao-basica/produtos-e-servicos/>.

Acesso em: 09 abr. 2014.

SARAIVA.

Histórico.

Disponível em: $<$ http://www.saraivari.com.br/conteudo_pt.asp?idioma=0\&conta=28\&tipo=496800>. Acesso em: 09 abr. 2014.

SHAIKH, A. La primeragrandepresióndelsiglo XXI. Sinpermiso, n.9, s/p, jul. 2011.

TARPON compra 20\% da Abril Educação. Folha de S. Paulo, São Paulo, 05 jun. 2014. Disponível em: <http://www1.folha.uol.com.br/fsp/mercado/169479-tarpon-compra-20-daabril-educacao.shtml >. Acessoem 05 jun. 2014. 
THE WORLD BANK.Operational Guidelines for textbooks and Reading materials.Education Sector: Washington, 2003.

TRIBUNAL DE CONTAS DO ESTADO DE SÃO PAUlO. Portal do Cidadão Pesquisa de Fornecedores. 2008-2014. Disponível em: <http://www.portaldocidadao.tce.sp.gov.br/despesa_fornecedor>. Acesso em: $20 \mathrm{fev}$. 2015.

\footnotetext{
${ }^{1}$ Mestranda em educação pela Faculdade de Educação da Unicamp, bolsista da Fundação de Amparo à Pesquisa do Estado de São Paulo (Fapesp). Contato: lucianasgalzerano@gmail.com.

${ }^{2}$ Este artigo é uma versão atualizada e modificada de resumo expandido apresentado em formato pôster no IV Seminário Internacional do Greppe: Privatização da Educação Básica na América Latina, realizado entre os dias 06 e 08 de agosto de 2014, na Faculdade de Educação da Unicamp; e de trabalho completo apresentado em formato de comunicação oral naXXI Jornada do Histedbr/X Seminário de Dezembro, realizado entre os dias 02 e 04 de dezembro de 2014, na Universidade Estadual do Maranhão - Centro de Estudos Superiores de Caxias.
}

${ }^{3}$ Segundo Marx (1991), há uma tendência gradual de queda na taxa média de lucro, pois quanto mais se desenvolvem as forças produtivas, sob o modo de produção capitalista, tende-se a reduzir o dispêndio de capital naquilo que é o elemento gerador de valor (e mais-valor): a força de trabalho. Para o autor, entretanto, esta é uma tendência e como tal sua averiguação ou adequação só ocorre na concretude histórica e no decurso de longos períodos. Além disso, a análise da realidade histórica mostra que há fatores contrários à lei, de modo que o capitalista possa compensar a queda naquela taxa com um aumento na massa de lucro produzida. O investimento no setor financeiro é um desses fatores. Para mais informações, ver Marx (1991), em especial os capítulos 13, 14 e 15 .

${ }^{4}$ No Ensino Fundamental são reutilizados por três anos os livros de História, Geografia, Ciências, Língua Portuguesa e Matemática, sendo repostos em caso de perdas, extravios e novas matrículas; são consumíveis os livros de Alfabetização Matemática e Alfabetização Linguística (para $1^{\circ}$ e $2^{\circ}$ anos) e Língua Estrangeira. No Ensino Médio são reutilizáveis, também por três anos, os de História, Geografia, Biologia, Química, Física e Língua Portuguesa, também havendo reposição; são consumíveis os de Língua Estrangeira e de Filosofia e Sociologia. (FNDE, 2014c).

${ }^{5}$ As editoras com participação menor do que $10 \%$ foram classificadas em "Outras". São elas: Nacional, Dimensão, Sarandi, Texto, Lafonte, Pearson, CDE, Casa Publicadora, Grafset, Terra Sul, Fapi, Zapt, Esfera, Ayamará, Educarte, Lê, UDP, AJS, CCS, Imperial, PAX, Base, Quinteto, Macmillan, Escala, Nova Geração, Positivo, Brasil, Ibep, Edições SM.

${ }^{6}$ Para mais informações, ver o verbete "sistema” em Adrião; Garcia (2010).

${ }^{7}$ Informações referentes aos anos mais recentes ainda necessitam ser coletadas.

${ }^{8}$ As empresas cuja participação foi menor do que 7\% foram classificadas em "Outras". Destacamos: OPET, FTD e Netbil.

${ }^{9}$ O Banco de Dados Parcerias Público-Privadas foi desenvolvido durante realização da pesquisa "Estratégias municipais para a oferta da educação básica: uma análise das parcerias público-privado no estado de São Paulo" (ADRIÃO, 2009) e atualizado durante a pesquisa "Sistemas Apostilados de Ensino e municípios paulistas: o avanço do setor privado sobre a política educacional local" (ADRIÃO, 2011). Seu acesso está disponível em:http://www.fae.unicamp.br/greppe/bd/pesquisas/pesqdados.php.

${ }^{10}$ Como principais diferenças entre o PNLD e a adoção de SPE, destacamos: 1) as instituições escolares não são obrigadas a seguir o passo a passo dos livros didáticos do PNLD, mas o são com os SPE; 2) os livros didáticos passam por avaliação realizada pelo MEC, o que não acontece com os materiais fornecidos pelos SPE; 3) a escolha dos SPE não necessariamente precisa passar pelos professores e instituições escolares, isto 
é, podem ser eleitos somente pelas gestões municipais, já o PNLD tem como foco a escolha pelos profissionais das escolas.

${ }^{11}$ O Centro de Estudos da Consultoria do Senado Federal foi criado pelo Ato da Comissão Diretora n ${ }^{\circ}$ 09, de 2007, e tem por objetivo aprofundar o entendimento de temas relevantes para a ação parlamentar (BRITTO, 2011, p.2).

${ }^{12}$ O Mobral era um projeto do governo federal, criado no fim da década de 1960, que propunha a alfabetização de jovens e adultos.

${ }^{13}$ De acordo com matéria divulgada pela Época Negócios, a Tarpon é um fundo de investimento brasileiro que, em 2013, era responsável pela gestão de aproximadamente 8 bilhões (OLIVEIRA; CAMPOS, 2013).

${ }^{14}$ No estado de São Paulo, onde a tendência à adoção desse tipo de política parece ter se iniciado, somente os sistemas Anglo e Maxi foram encontrados. Mais informações a respeito dos demais sistemas, também em outros estados, ainda deverá ser investigada.

${ }^{15}$ Trecho original: "Textbooks and reading materials are key in service achieving pedagogical out comes at all levels of education and training, which are in turn necessary for developinghuman resources for economic development and poverty reduction".

${ }^{16}$ Trecho original: "The textbook is limited in that it is no the full curriculum. However, in countries where teachers are not well trained and where no other learning materials are in school, the textbook effectively becomes the curriculum".

Recebido: jun/2015 Aprovado: jul/2015 